Polymer Journal Vol. 1, No. 6, pp 669-674 (1970)

\title{
Alternating Copolymerization of Isoprene and Methyl Methacrylate
}

\author{
Eizo Oikawa and Ken'ichi Yamamoto \\ Faculty of Engineering, Niigata University, \\ Nagaoka, Niigata, Japan.
}

(Received June 11, 1970)

\begin{abstract}
The copolymerization of isoprene and methyl methacrylate was studied in the presence of either a radical catalyst or zinc chloride without a catalyst. The occurrence of radical copolymerization was confirmed from NMR spectroscopy. Monomer reactivity ratios were determined in the radical copolymerization: $r_{I P}=0.78 \pm 0.13$, $r_{\mathrm{MMA}}=0.4 \pm 0.1$. They were comparable with those of the butadiene-methyl methacrylate copolymerization. In the presence of zinc chloride the copolymerization took place without a radical catalyst and the complex formation of methyl methacrylate with zinc chloride was necessary to give reproducible results. The copolymer formed had an almost 1:1 monomer composition irrespective of the monomer feed ratio, indicating that the copolymer was alternating. The configuration in the repeating unit of the alternating copolymer was discussed on the basis of NMR spectra and specified in comparison with the spectra of the copolymers, cyclic Diels-Alder adducts of isoprene and methyl methacrylate, and the copolymer of 2,3-dimethylbutadiene and methyl methacrylate. Isoprene was present essentially in the 1,4-trans structure in the alternating copolymer.

KEY WORDS Isoprene/Methyl Methacrylate/Monomer Reactivity Ratio / Zinc Chloride / Alternating Copolymer / Copolymer Configuration / NMR / Diels-Alder Adduct / 2,3-Dimethylbutadiene /
\end{abstract}

Radical copolymerizations of conjugated dienes with acrylonitrile have been extensively studied in solution or emulsion phase. However, the copolymerization of isoprene (IP) with methyl methacrylate (MMA) possessing a conjugated and electron-withdrawing carbonyl group, instead of a nitrile group for acrylonitrile, has received little attention, while butadiene has been successfully copolymerized with MMA. ${ }^{1,2}$ In the presence of ethylaluminium sesquichloride or zinc chloride the polymerization of conjugated dienes with acrylonitrile has given alternating copolymers. ${ }^{3,4}$ An analogous production method of an alternating copolymer of conjugated dienes and MMA has been reported but seems to require either organoaluminium compounds or a strong Lewis acid like aluminium chloride. ${ }^{5}$

In the present study the copolymerization of IP with MMA complexed with a mildly active Lewis acid, zinc chloride, was investigated. The complex formation of MMA with zinc chloride could yield an alternating copolymer in the absence of a radical catalyst and the configuration of the copolymer sequence was compared by NMR spectroscopy with that of the copolymer of IP and MMA prepared with a radical catalyst.

\section{EXPERIMENTAL}

\section{Materials}

Isoprene and methyl methacrylate of commercially available extra pure grade were distilled before use. Zinc chloride of guaranteed grade was used after it had been dried under vacuum at $180^{\circ} \mathrm{C}$ for $10 \mathrm{hr}$. 2,3-Dimethylbutadiene (DMB) was prepared by dehydration of pinacol with hydrobromic acid. ${ }^{6}$

\section{Methyl Methacrylate-Zinc Chloride Complex}

The MMA-zinc chloride complex was prepared by shaking vigorously the mixture of zinc chloride and MMA in 1:5 molar ratio in an atmosphere of nitrogen at room temperature for several hours in the dark until zinc chloride was dissolved and by distilling the excess of MMA under reduced pressure until the weight reached that which corresponded to the molar ratio $\left(\mathrm{MMA}_{\mathrm{ZnCl}}\right.$ ) of $2 / 1$. The exact composition of the transparent and viscous complex was determined from chlorine content by the Volhard method. 


\section{E. Oikawa and K. Yamamoto}

\section{Copolymerization}

In a dry box the complex was placed in a flask previously flushed with nitrogen, and then the required amout of IP was added. The content of the stoppered flask was stirred magnetically at $20^{\circ} \mathrm{C}$. After the reaction time the mixture was poured into an excess of methanol to precipitate the copolymer. Reprecipitation from the dioxane-water system two to four times could remove zinc chloride. No ash was left behind on combustion. The copolymer was then extracted with $n$-heptane for $20 \mathrm{hr}$, followed by washing with nitromethane. The copolymer was finally freeze-dried from a benzene solution. The monomer ratio in the copolymers was calculated from elemental analysis and the areas for methoxy (MMA) peak at 6.59 $\tau$ and methyl (IP) peak at $8.40 \tau$ in NMR spectra.

The radical copolymerization was carried out with a low yield in 20 -wt $\%$ monomers in benzene with $1 \mathrm{~mol} \%$ (based on monomers) of azobisisobutyronitrile in an oxygen-excluded glass ampule at $80 \pm 0.5^{\circ} \mathrm{C}$ for $6-10 \mathrm{hr}$. The benzene solution was poured into methanol to precipitate the copolymer, which was then reprecipitated several times from benzene-methanol and dried under reduced pressure at $30^{\circ} \mathrm{C}$. The monomer ratio was obtained from elemental analysis and NMR spectra.

The copolymerization of DMB with MMAzinc chloride complex was carried out similarly as in the case of IP and MMA-zinc chloride.

Diels-Alder Adducts of Isoprene and Methyl Methacrylate

In the presence of aluminium chloride the procedure for the preparation of IP-methyl acrylate adduct was followed. ${ }^{7}$ Thus, to a suspension of $3.4 \mathrm{~g}$ of aluminium chloride in
$125 \mathrm{ml}$ of benzene warmed at $50^{\circ} \mathrm{C}$ was added $15.2 \mathrm{~g}$ of MMA in $25 \mathrm{ml}$ of benzene, followed by a slow addition of $20.4 \mathrm{~g}$ of IP. The mixture was stirred at $50-60^{\circ} \mathrm{C}$ for $3 \mathrm{hr}$, washed with 5-10\% aqueous hydrochloric acid and water, and dried over anhydrous sodium sulfate overnight. The distillation under reduced pressure gave Adduct $\mathrm{A}$ at $45.3-\%$ yield. It boiled at $97-98^{\circ} \mathrm{C} / 20 \mathrm{mmHg}$ and consisted of methyl 1,4-dimethyl-3-cyclohexene-1-carboxylate (4-isomer, IV) and methyl 1,3-dimethyl-3-cyclohexene1-carboxylate (3-isomer, V) in a ratio of 91.4: 8.6. The reaction in the absence of a catalyst in 70-\% benzene solution in a sealed tube at $100^{\circ} \mathrm{C}$ for $24 \mathrm{hr}$ brought about a 64.4:35.6 product, Adduct B, at $18 \%$ yield. These ratios were evaluated from gas chromatography with a 7-m column of tricresyl phosphate at $120^{\circ} \mathrm{C}$. In the distillation of Adduct $B$, no appreciable difference in the composition was found between the initial and the final distillate by gas chromatography.

\section{NMR Spectra}

The spectra were recorded with a Japan Electron Optics Lab. Model JNM-4H-100 high resolution spectrometer at $100 \mathrm{MHz}$ in $\mathrm{C}_{6} \mathrm{D}_{6}$. solution at room temperature, with tetramethyl silane as an internal standard.

\section{RESULTS AND DISCUSSION}

The results of the copolymerization are tabulated in Tables I and II, and shown in Figure 1. NMR spectra of the radical copolymers of different compositions are shown in Figure 2. The appearance of new peaks at 7.32, 7.46 and $7.55 \tau$ in (c), which are not seen in the IP- and MMArich copolymers, indicates that they originated

Table I. Radical copolymerization of isoprene and methyl methacrylate

\begin{tabular}{|c|c|c|c|c|c|c|}
\hline \multirow{2}{*}{ No. } & \multirow{2}{*}{$\begin{array}{l}\text { IP in monomer } \\
\text { mixture, } \\
\text { mol } \%\end{array}$} & \multirow{2}{*}{$\underset{\mathrm{hr}}{\text { Time, }}$} & \multirow{2}{*}{$\underset{\%}{\text { Yield, }}$} & \multicolumn{2}{|c|}{ Analysis, \% } & \multirow{2}{*}{$\begin{array}{l}\text { IP in copolymer } \\
\text { mol } \%\end{array}$} \\
\hline & & & & $\mathrm{C}$ & $\mathrm{H}$ & \\
\hline RI-1 & 10.0 & 6 & 4.0 & 62.32 & 8.52 & 11.6 \\
\hline RI-2 & 29.4 & 8 & 4.3 & 69.81 & 9.47 & 43.9 \\
\hline RI-3 & 49.9 & 10 & 9.7 & 72.72 & 10.12 & 54.7 \\
\hline RI-4 & 70.3 & 6 & 8.6 & 77.88 & 10.45 & 71.7 \\
\hline RI-5 & 90.5 & 8 & 10.7 & 83.27 & 11.19 & 87.3 \\
\hline
\end{tabular}

a AIBN, $1 \mathrm{~mol} \%$ based on monomers, at $80^{\circ} \mathrm{C}$. 
Alternating Copolymerization of Isoprene and Methyl Methacrylate

Table II. Copolymerization of isoprene or 2,3-dimethylbutadiene with methyl methacrylate-zinc chloridea

\begin{tabular}{|c|c|c|c|c|c|c|c|c|}
\hline \multirow{2}{*}{ No. } & \multirow{2}{*}{$\begin{array}{l}\text { IP in } \\
\text { monomer } \\
\text { mixture, } \\
\text { mol } \%\end{array}$} & \multirow{2}{*}{$\underset{\text { hr }}{\text { Time }}$} & \multirow{2}{*}{$\underset{\%}{\text { Yield,b }}$} & \multicolumn{2}{|c|}{ Analysis, ${ }^{\mathrm{c}} \%$} & \multicolumn{2}{|c|}{$\begin{array}{l}\text { Copolymer composition, } \\
\text { mol } \% \text { IP }\end{array}$} & \multirow{2}{*}[\eta]{$^{\Theta}$} \\
\hline & & & & $\mathrm{C}$ & $\mathbf{H}$ & From $\mathrm{C} \%$ & From NMR $^{\mathrm{d}}$ & \\
\hline IA-1 & 30.1 & 6 & 3.0 & 70.34 & 9.50 & 46.3 & 49.5 & 0.28 \\
\hline IA-2 & 44.5 & 4.3 & 3.6 & 70.48 & 9.22 & 46.8 & 47.6 & 0.78 \\
\hline IA-3 & 50.0 & 4.5 & 6.6 & 71.23 & 9.74 & 49.3 & 47.6 & 0.46 \\
\hline IA-4 & 70.0 & 2.5 & 2.0 & 71.26 & 9.70 & 49.7 & 47.6 & 0.27 \\
\hline IA-5 & 89.8 & 0.75 & 0.3 & 69.78 & 9.49 & 44.2 & 45.6 & 0.24 \\
\hline $\mathrm{DA}-1^{\mathrm{f}}$ & $50.0^{\mathrm{g}}$ & 3 & 13.7 & 72.28 & 10.09 & 50.5 & 51.2 & \\
\hline
\end{tabular}

a $\mathrm{MMA} / \mathrm{ZnCl}_{2}=2.0$ (molar ratio), at $20^{\circ} \mathrm{C}$.

b After the extractions.

c Calcd for 1: 1 copolymer: C, $71.42 \% ; \mathrm{H}, 9.52 \%$.

d Based on methoxy (MMA) peak at $6.59 \tau$ and methyl (IP) peak at $8.40 \tau$; two methyl (DMB) peaks at 8.20 and $8.30 \tau$ for DA-1.

e In benzene at $25 \pm 0.05^{\circ} \mathrm{C}$.

f $\mathrm{MMA} / \mathrm{ZnCl}_{2}=1.67$.

g 2,3-Dimethylbutadiene.

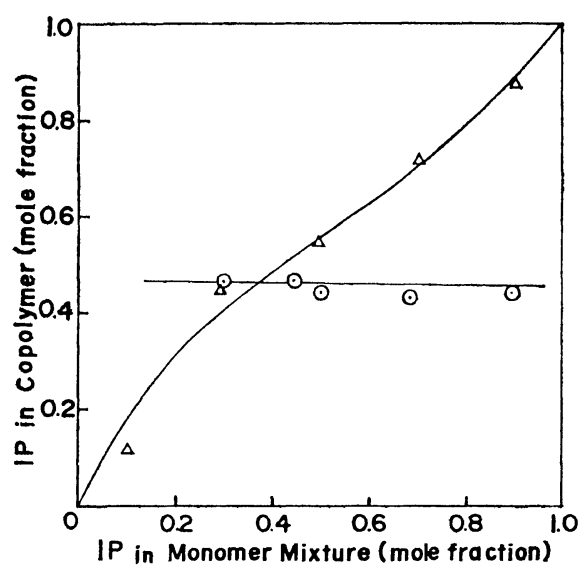

Figure 1. Copolymerization curve of IP-MMA with AIBN $\left(\triangle\right.$, Table I) and with $\mathrm{ZnCl}_{2}(\odot$, Table II).

from IP-MMA diads as a result of the increase in the number of IP-MMA linkages; i.e., the copolymerization of IP and MMA took place. Monomer reactivity ratios obtained from the curve with AIBN in Figure 1 are $r_{I P}=0.78 \pm$ 0.13 and $r_{\mathrm{MMA}}=0.4 \pm 0.1$. These are close to the results of the copolymerization of butadiene and MMA: $r_{\mathrm{B}}=0.75, r_{\mathrm{MMA}}=0.25^{1}$ and $r_{\mathrm{B}}=$ $0.70, r_{\text {MMA }}=0.32 .^{9}$

As may be seen from Figure 1, the composition of the polymers obtained with zinc chloride is independent of the initial monomer ratio and the product of the monomer reactivity ratio

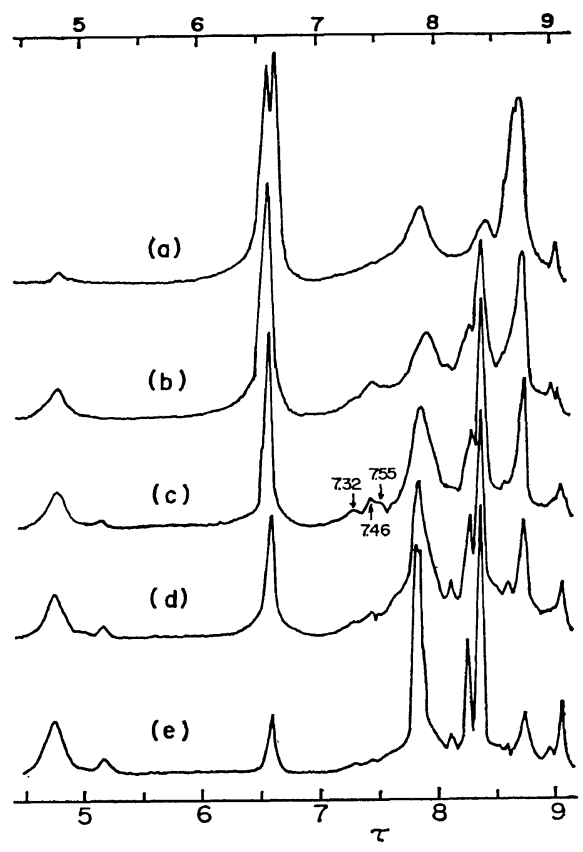

Figure 2. NMR spectra of radical IP-MMA copolymers (mol\% IP): (a), RI-1 (11.6); (b), RI-2 (43.9); (c), RI-3 (54.7); (d), RI-4 (71.7); (e), RI-5 (87.3).

will obviously be close to zero, indicating that the copolymer is alternating.

Some procedures have been reported ${ }^{10}$ in which either an excess of a donor monomer (2-methyl1-pentene or IP) is added to an equimolar 


\section{E. Oikawa and K. Yamamoto}

mixture of an acceptor monomer (acrylonitrile) and zinc chloride without a radical catalyst, or the acceptor is used also as a solvent with a radical catalyst. Application of the procedures to the present study failed to produce copolymers of reproducible monomer composition because the above technique was sometimes accompanied by homopolymerization of MMA. However, the complex formation of MMA with zinc chloride prior to the copolymerization could cause such a failure to be avoided. The same technique has been employed in the copolymerization of styrene and MMA or acrylonitrile. ${ }^{11}$ The extraction with $n$-heptane and nitromethane gave an extract having a considerable content of the copolymer, according to infrared spectroscopy, since the extract showed a similar pattern to that of the copolymer, and, therefore, it is reasonable to consider that most of the homopolymers should have been included in the extract, if indeed there were any at all.



Figure 3. NMR spectra of (a) radical copolymer (Figure 2c), (b) alternating copolymer (IA-1), and (c) DMB-MMA copolymer (DMB/MMA = 50.5/ 49.5 in mole).

The NMR spectrum of a copolymer prepared in the presence of zinc chloride is shown in Figure 3, for comparison with that of a radical copolymer having a composition close to $1: 1$ and of the copolymer of DMB and MMA. As is seen from Table II, the DMB-MMA copolymer has a $1: 1$ monomer composition and is considered to be alternating in view of an electron-donating abilility of DMB comparable with isoprene.

The absorptions for the alternating copolymer of IP and MMA in Figure $3 \mathrm{~b}$ can be assigned as follows: $4.78 \tau$ for methine proton $=\mathrm{CH}_{-}$, $6.59 \tau$ for methoxy protons $\mathrm{OCH}_{3}, 7.32-8.10 \tau$ for methylene protons $\mathrm{CH}_{2}, 8.40 \tau$ for IP methyl protons $\mathrm{CH}_{3}$ (IP) and $8.80 \tau$ for MMA methyl protons $\mathrm{CH}_{3}$ (MMA). A similar assignment can be made for the radical copolymers in Figure 2, where, in addition, a small absorption at $5.18 \tau$ is ascribed to methine protons due to 1,2 addition of IP and splitting at $8.30 \tau$ to methyl protons due to 1,4-cis addition of IP. With polyisoprene in benzene, the chemical shift of methyl protons at a lower field $8.21 \tau$ has been assigned to 1,4-cis configuration and that at an upper field $8.35 \tau$ to 1,4-trans configuration. ${ }^{12}$ The complete absence of both the splitting and the absorption at $5.18 \tau$ and the presence of a chemical shift at $8.40 \tau$ in Figure $3 \mathrm{~b}$ suggest that IP is present essentially in 1,4-trans structure in the alternating copolymer. In Figure 3 methylene protons of (a) have only one broad peak at $7.87 \tau$ even at $70^{\circ} \mathrm{C}$, whereas those of (b) split into two distinct peaks at 7.83 and $7.98 \tau$, indicating that the alternating copolymer has a regulated conformation and nonequivalent methylene protons.

There are two possible configurations I and II, in the repeating unit of the alternating copolymer. An attempt to determine which configuration corresponds to the actual alternating copolymer was made by comparing NMR spectra of Diels-Alder adducts A and B with those of the copolymers. NMR spectra of Adducts A and $B$ are shown in Figure 4. In the spectrum of Adduct B three peaks appeared in the methylene region at $7.26,7.42$ and $7.57 \tau$, similar to those in Figure $3 \mathrm{a}$ at $7.32,7.46$ and $7.55 \tau$. This suggests that IP-MMA diad with the head-to-head configuration also exists in the radical copolymers, because Adduct $B$ can be regarded as a mixture of head-to-head and headto-tail configurations. The spectrum (b) in Figure 3 possessing two separate peaks at 7.32 and $7.46 \tau$ has a pattern similar to that of Adduct 




Figure 4. NMR spectra of Adducts. (a) Adduct A (4-isomer (IV): 3-isomer $(\mathrm{V})=91.4: 8.6)$; (b), Adduct B (4-isomer : 3-isomer $=64.4: 35.6$ ).

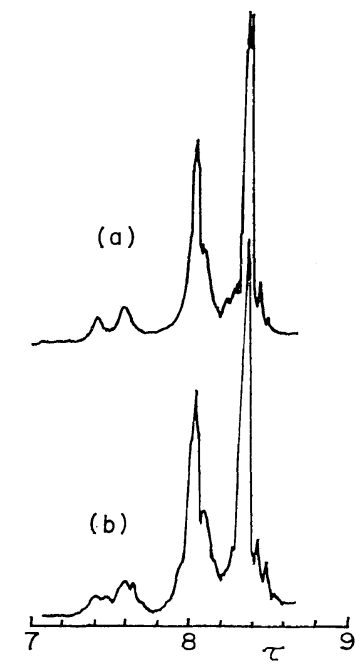

Figure 5. NMR spectra of (a) Adduct $A$ and (b) Adduct $\mathrm{B}$ in $\mathrm{CDCl}_{3}$ at room temperature.

A $(7.26$ and $7.42 \tau)$. The sum of the area of these two peaks corresponds to one proton in both cases, and furthermore, the ratio of peak area at $4.78 \tau, 7.32$ plus $7.46 \tau$ and 7.83 plus $7.98 \tau$ in Figure $3 \mathrm{~b}$ is $1: 1: 5$, and the same ratio is the case for $4.70 \tau, 7.26$ plus $7.42 \tau$ and other methylene peaks in the upper field in Figure 4a. The peaks 7.32 and $7.46 \tau$ are ascribed to



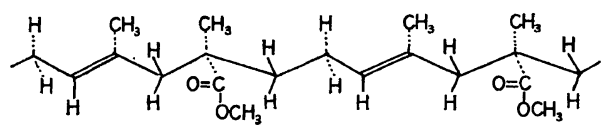

II



III
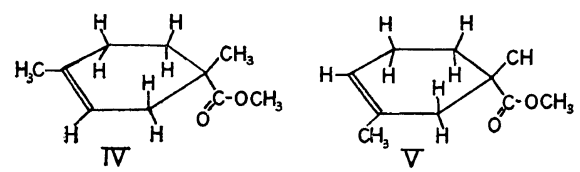

spin-spin coupling because a $60-\mathrm{MHz}$ spectrum had shifted absorptions at 7.26 and $7.49 \tau$ with the unaltered interval $(14 \mathrm{cps})$. Two other methylene peaks 7.83 and $7.98 \tau$ in Figure $3 \mathrm{~b}$ may also be due to spin-spin coupling because they shifted to 7.78 and $8.00 \tau$ in the $60-\mathrm{MHz}$ spectrum. Since the rotation of a carboncarbon single bond in a cyclic compound is very restricted analogously to the case of the stereoregulated alternating copolymer, the interval 16 cps $((7.42-7.26) \times 100)$ for the coupling in Adduct $\mathrm{A}$ is possible when a carbon-carbon double bond neighbors on the spin-spin coupling system. A third distinct absorption at $7.57 \tau$ in Figure $4 \mathrm{~b}$ can apparently be ascribed to 3isomer, $\mathrm{V}$, because Adduct $\mathrm{B}$ differs from Adduct A only in proportion of $\mathrm{V}$; i.e., the former has a larger proportion of $\mathrm{V}$ than the latter. Another peak due to $\mathrm{V}$ which pairs with $7.57 \tau$ may exist and be overlapped with $7.42 \tau$. This is illustrated in the spectra in $\mathrm{CDCl}_{3}$ in Figure 5. The chemical shift of the proton of $\mathrm{V}$ is then about $7.50 \tau(1 / 2(7.57+7.42))$ in Figure $4 b$, provided that a coupling of the $\mathrm{AB}$ type is assumed. This is very close to the methylene peak $7.52 \tau$ of the DMB-MMA copolymer III. The peak $7.52 \tau$ may be one of a doublet, the other being overlapped at an upper field in view of the shoulder at $7.70 \tau$ in Figure 3c. In any case, however, methylene protons of the DMB-MMA copolymer are significantly shifted to the upper 


\section{E. Oikawa and K. Yамамото}

field, probably because of methyl groups neighboring on methylene protons. The absence of vinylene protons in the vicinity of $5.0 \tau$ rules out the 1,2-structure of DMB.

Consequently, it is clear that the two absorptions 7.32 and $7.46 \tau$ of the alternating copolymer are ascribed to the methylene protons between the carbon-carbon double bond and the MMA tertiary carbon that has a carbonyl group. Both the double bond and the carbonyl group can cause a shift to the lower field. Since the peak area of 7.32 plus $7.46 \tau$ equals one proton and the latter peak at an upper field is always higher than the other both in Figures $3 b$ and $4 a$, they are most likely to be the left half of $\mathrm{AB}$ quartets.

If a methyl group is attached to the doublebond carbon adjacent to the methylene groups, their absorptions would be shifted to an upper field because of the electron-donating property of the methyl group. This agrees with the fact that the spectrum of Adduct $B$ has a new absorption due to $\mathrm{V}$ at an upper field of $7.57 \tau$ in Figure $4 \mathrm{~b}$ and two overlapping peaks in Figure $5 b$.

From the discussion above it may be concluded that the IP-MMA alternating copolymer actually has sequence $I$ and the absorptions at 7.32 and $7.46 \tau$ may stem from rather complicated couplings of $\mathrm{H}_{\mathrm{A}}$ and $\mathrm{H}_{\mathrm{B}}$ in $\mathrm{I}$ with each other and with adjacent protons. The actual occurrence of the configuration I may be expected from a common point of the effective preparation of the alternating copolymer and Diels-Alder adduct IV with a Lewis acid. The above analysis of NMR spectra, however, could give more reliable evidence.

The trans structure of IP incorporated in I is apparent from the fact that the methine proton
$(4.78 \tau)$ in Figure $3 b$ is shifted to an upper field $^{13}$ compared with $4.70 \tau$ for the cyclic cis adducts, as well as $8.40 \tau$ for methyl protons with no splitting into $8.30 \tau .^{12}$

Acknowledgement. The authors wish to express their gratitude to Japan Electron Optics Lab. for NMR measurements at $60 \mathrm{MHz}$ in $\mathrm{C}_{6} \mathrm{D}_{6}$.

\section{REFERENCES}

1. F. M. Lewis, C. Walling, W. Cummings, E. R. Briggs, and W. J. Wenisch, J. Amer. Chem. Soc., 70, 1527 (1948).

2. C. Walling and J. A. Davidson, ibid., 73, 5736 (1951).

3. J. Furukawa and Y. Iseda, J. Polym. Sci., Part B, 7, 47 (1969).

4. N. G. Gaylord and A. Takahashi, ibid., 7, 443 (1969).

5. K. Haga and Y. Iseda, S. African Patent 6808473 (1969).

6. C.F.H. Allen and A. Bell, "Organic Syntheses," Coll. Vol. 3, John Wiley \& Sons, New York, N.Y., 1955, p 312.

7. T. Inukai and M. Kasai, J. Org. Chem., 30, 3567 (1965).

8. V. F. Kucherov, A. S. Onishchenko, B. A. Rudenko, and E. A. El'perina, Doklad. Akad. Nauk SSSR, 158(2), 397 (1964); Chem. Abstr., 62, 7630c (1965).

9. M. F. Margaritova and V. A. Raiskaya, Tr. Mosk. Inst. Tonkoi Khim. Tekhnol., 4, 37 (1953); Chem. Abstr., 49, 14372h (1955).

10. G. E. Serniuk, et al., U.S. Patent 3278503 (1966).

11. T. Ikegami and H. Hirai, J. Polym. Sci., Part $A-1,8,463$ (1970).

12. H. Y. Chen. Anal. Chem., 34, 1793 (1962).

13. R. C. Ferguson, J. Polym. Sci., Part A, 2, 4735 (1964). 